\title{
Understanding technical cleanliness: importance, assessment, maintenance
}

ARTICLE INFO

Received: 15 July 2021

Revised: 26 July 2021

Accepted: 26 July 2021

Available online: 27 July 2021
Development of the automotive industry, including so-called dowsizing and rightsizing, entails the need to ensure, and hence to verify, the stringent cleanliness levels of an increasing number of car components. The assurance of proper cleanliness level requires knowledge of the entire production process and precise information on the contaminants that will allow to identify their sources. Obtaining reliable cleanliness information requires establishing of many different factors, $i$. a. selection of proper contamination extraction and collection technique, proper parameters of extraction, validation of extraction procedure, methods of particles analysis. Analytical techniques which are implemented include gravimetric, optical microscopy and advanced techniques like scanning electron microscopy. This work present's actual state of knowledge regarding technical cleanliness analysis of components. Important aspects of $Q A \& Q C$ in technical cleanliness assessment are also discussed.

Key words: technical cleanliness, component cleanliness code, contaminations, particles, optical microscopy, SEM

This is an open access article under the CC BY license (http://creativecommons.org/licenses/BY/4.0/)

\section{Introduction to technical cleanliness}

The automotive industry, one of the biggest industries in the world, is still developing, which is rather a need than a wish. This development includes works not only on compact engines and gearboxes without decreasing their power (so-called downsizing), but also on new light materials, i.e. lightweight metals, what entails necessity of using different materials processing [1]. Global trends in environmental protections, which result in introducing restrictive regulations, also force the need of improvement and development.

Therefore, when talking about downsizing, the need of ensuring and verifying the stringent cleanliness levels of an increasing number of car components is necessary.

Technical cleanliness can be defined as:

- a present state of components cleanliness, that means the presence of different contaminations on internal or external area, or on both areas,

- a process of ensuring cleanliness of components from their manufacturing, storage, packing to transportation to end user [2],

- a process of components cleaning in order to check their cleanliness level.

Confirmation of the importance of technical cleanliness topic is the fact, that international standard ISO 16232 dedicated to automotive industry, was developed [3] which is very similar to VDA 19.1 standard [4] developed by German Association of the Automotive Industry. The aim of both standards is to establish comparative methods for cleanliness assessment, including extraction procedure, test fluid, cleaning parameters settings, and analytical instruments, and to establish universal Component Cleanliness Code (CCC) [3, 4]. Moreover, car producers and component producers, also have their own, internal standards or technical specifications, which precise and expand cleaning processes, but first of all, which define cleanliness level requirements. ISO standard is more worldwide used, for that reason this standard will be cited in present work as the basis.
According to [3], modern automotive components and systems are sensitive to presence of single or a few critically sized particles. The presence of foreign particles is especially crucial in case of any flow system in vehicle, pressurized or not, and with extreme importance in all injections systems. Particles such as sand, metals, machining chips or abrasive residues may have negative impact on proper component or assembly functioning, i.e. by its damaging effect, increased wear or rapid corrosion occurrence $[5,6]$. As a standard, particles ranged from $15 \mu \mathrm{m}$ to $1000 \mu \mathrm{m}$ are under control [2], but, in some cases, the presence of particles as small as $5 \mu \mathrm{m}$ may result in components damage [7].

In fact, the function of the component in vehicle determines the level of permissible particle types and sizes. However, as the internal cleanliness of the components has huge effect on whole car performance, operation and safety of the driver and passengers, its importance declines fast after the vehicle is put to the service. After successful start of operation, the importance of cleanliness is reoriented to external sources such as fuels and oils [8-10]. The level of contaminations in these fluids, as the most frequently refilled or exchanged in the vehicle, is well established, described and understood, as it needs to fulfill and excel all cars technical limitations. The importance of these fluids' cleanliness is of great interest, and remains an attractive research topic [11-13]

The assurance of proper cleanliness level of any product requires knowledge of the entire production process and precise information on the contaminants, that will allow to identify their sources. Avoiding product contamination requires awareness of all operations in process that influence the product's cleanliness level. This leads to stringent productions regimes, including assembly operations to be performed in clean areas, separated from production lines, or even in cleanrooms. However, the requirements are based on engineering needs and technical premises, the product should be as good (in this case - clean) as required, 
and not necessarily better because every change and every new operation carries additional costs.

In order to get knowledge about cleanliness level of component, laboratory tests in special cleanrooms are required. Obtaining reliable information requires establishing of many different factors, i.a.:

- selection of proper contamination extraction and collection technique (i.e. pressure rinsing, ultrasound-assisted extraction, flushing, shaking, and others),

- proper parameters of extraction,

- validation of extraction procedure (declining performance),

- methods of particles analysis.

Analytical techniques which are implemented include [14]:

- gravimetric analysis (total amount of all particles collected from component, expressed in $\mathrm{mg} / \mathrm{component}$, $\mathrm{mg} / \mathrm{cm}^{2}$ or $\mathrm{mg} / \mathrm{cm}^{3}$ ),

- optical microscopy (granulometry, that means determination of number, sizes and types of particles, including division into metallic, non-metallic and fibrous particles),

- advanced techniques, like scanning electron microscopy (SEM, allowing for determination of elemental composition and hardness of particles).

The aim of present work is to present actual state of knowledge regarding technical cleanliness of components, required analytical techniques to perform cleanliness test in laboratory in order to check the compliance with specific customer's requirements. Important aspects of QC\&QA in technical cleanliness assessment will also be discussed.

\section{Technical cleanliness inspection}

Cleanliness inspection starts as soon as component leave production line, but proper cleanliness level should be ensured just during production process. Each next step in component life has to be taken into account in order to obtain reliable results. In the end it will help to verify the effectiveness of actions taken for assuring the required cleanliness level.

Before transfer of component to laboratory, it has to be properly protected and packed. It is especially important step, because it should be ensured that none of the particle may be lost and in reverse: no foreign particles can contaminate the component. Awareness of the matter and sources of potential foreign contaminations is required to conclude about whole process state and improvement. Therefore, also laboratory room in which inspection will be carried out need to assure proper cleanliness level in order to avoid cross-contamination of tested object and filters with foreign particles. Such laboratories are called cleanrooms and may be also used on production lines if very strict requirements regarding the cleanliness level of produced part apply. These areas are governed by the need of avoiding foreign contaminations presence and according to ISO 14644-1 [15] are coded from ISO 1 class (the most stringent requirements) to ISO 9 class (the least stringent) cleanroom. Example of BOSMAL's ISO 6 class cleanroom is presented in Fig. 1.

First of all, even during project of component and production line, cleanliness requirements need to be known. Both in ISO/VDA standards, and in different OEMs speci- fications definitions of particles are different. Moreover, also division of particles and requirements regarding their allowable sizes are different. For that reason, for technical cleanliness assurance and assessment all parameters, that mean target values, are needed:

- type of particles: metallic, non-metallic, fibers, hard particles, soft particles,

- allowable sizes (minimum size of particle),

- allowable number of particles,

- additional requirements for particles (chemical composition, hardness, height, area etc.).

Examples of different definitions of particle (contaminant) are presented in Table 1 with some photographic documentation, from optical microscope, of different particles with division into hard and soft, found during BOSMAL laboratory practice is presented in Figs 2-4. As can be seen, it is possible to differentiate particles on the basis of their microscopic appearance.

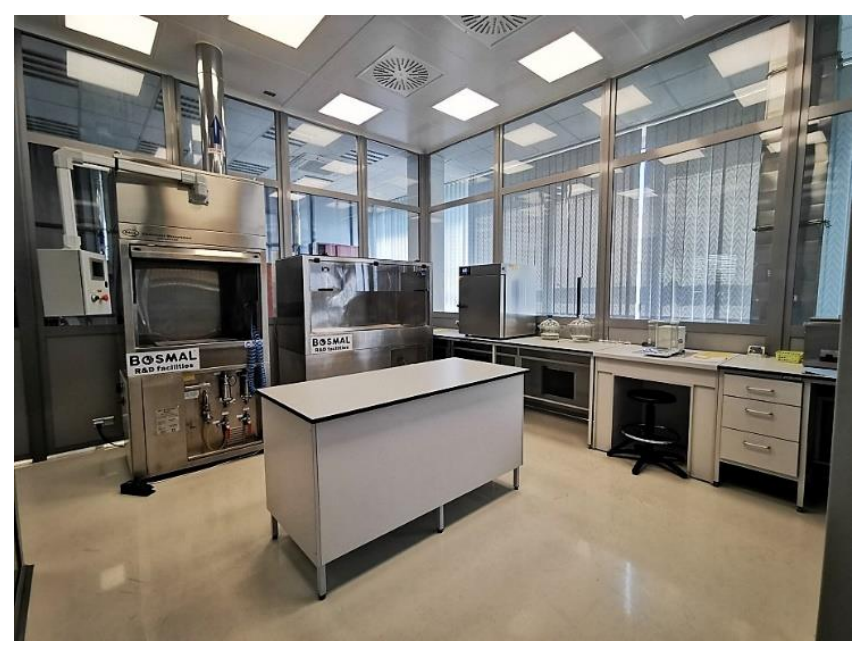

Fig. 1. BOSMAL's ISO 6 class cleanroom equipped with pressure rinsing equipment, ultrasonic bath, analytical balance, temperature chamber and filtration equipment

Despite multiplicity of extraction methods, types and meshes of filters used for particles collection, and then analytical methods involved, laboratory cleaning procedure may be described in few general steps (Fig. 5). The main steps are: equipment and filters preparation, blank value check, cleaning procedure, gravimetric analysis, microscopic analysis, test report preparation.

Technical cleanliness inspection is a kind of indirect test as it requires transport of particles from analyzed surface onto the filter on which detailed analysis is performed. This transport is necessary as the visual inspection of the component inner surface is usually difficult due to object's geometry, base material, visual similarities component with contaminations, surface roughness etc. [3]. Choosing proper extraction method is crucial in order to get reliable information regarding the cleanliness level. Extraction method should ensure transport of all particles from the tested surface to the filter. Even though that in real life not all particles will be deposited on filter, and some of them may remain on tested object, in extraction equipment or will be too small to be stopped by the filter mesh, extraction is 
Table 1. Different definitions of contaminants

\begin{tabular}{|c|c|c|c|c|}
\hline $\begin{array}{l}\text { Standard/ } \\
\text { OEM }\end{array}$ & \multicolumn{2}{|l|}{ Particles } & Fibers & Ref. \\
\hline $\begin{array}{l}\text { ISO } 16232 / \\
\text { VDA } 19.1\end{array}$ & \multicolumn{2}{|c|}{ tiny structure made from solid organic or inorganic matter } & $\begin{array}{l}\text { long, thin structure, stretched } \\
\text { length to maximum inner circle } \\
\text { diameter ratio is } \geq 20 \text {; the width } \\
\leq 50 \mu \mathrm{m}\end{array}$ & {$[3,4]$} \\
\hline VW & $\begin{array}{l}\text { Hard particles: metallic particles (incl. shiny } \\
\text { and non-shiny: corroded, oxidized); non-metallic } \\
\text { abrasive (sand, blasting and grinding particles, } \\
\text { other abrasive particles) }\end{array}$ & $\begin{array}{l}\text { Soft particles: non-metallic, } \\
\text { non-abrasive }\end{array}$ & $\begin{array}{l}\text { Fibers: cotton fibers, metallic } \\
\text { fibers, glass fibers }\end{array}$ & [16] \\
\hline BMW & \multicolumn{2}{|c|}{$\begin{array}{l}\text { Hard particles - mineral (H1): of mineral, ceramic nature (corundum } \mathrm{Al}_{2} \mathrm{O}_{3} \text {, silicon } \\
\text { carbide } \mathrm{SiC} \text {, boron nitride } \mathrm{BN} \text {, Diamond } \mathrm{C} \text {, sand } \mathrm{SiO}_{2} \text {, further nitrides, oxides, } \\
\text { carbides, further minerals and ceramics, glass, glass fibers, mineral fibers } \\
\text { Hard particles - metallic }(\mathrm{H} 2) \text { : steel, hard coating materials (wear resistance coat- } \\
\text { ings) }\end{array}$} & & [17] \\
\hline $\begin{array}{l}\text { Mercedes- } \\
\text { Daimler }\end{array}$ & \multicolumn{2}{|c|}{$\begin{array}{l}\text { Residual dirt: machining chips, sand, blasting shot residues, metals, abrasive resi- } \\
\text { dues, lint, paint, plastic particles }\end{array}$} & & [18] \\
\hline GM & \multicolumn{2}{|c|}{ Burrs and loose chips resulting from machining operations, casting processes etc. } & & [19] \\
\hline Volvo & $\begin{array}{l}\text { Solid matter } \\
\text { Hard particles: harder than soft particles }\end{array}$ & $\begin{array}{l}\text { Soft particles: i.e. textile, lint, } \\
\text { paper, plastics, foil, hair }\end{array}$ & $\begin{array}{l}\text { Particle with length/diameter } \\
\text { ratio: } \geq 20: 1, \text { minimum length: } \\
500 \mu \mathrm{m}\end{array}$ & [20] \\
\hline Scania & $\begin{array}{l}\text { Hard particles: machining chips, general metallic } \\
\text { particles, blasting shot media, foundry residue, } \\
\text { sand, ceramics, hard oxides, abrasive residues, } \\
\text { hard coating materials, amorphous glass particles }\end{array}$ & $\begin{array}{l}\text { Soft particles: coating/paint } \\
\text { particles, oxide flakes, plastics, } \\
\text { wood particles, agglomerated } \\
\text { fibers, chemical residues }\end{array}$ & $\begin{array}{l}\text { Single elongated, soft particles, } \\
\text { with the Feret max:Feret min } \\
\text { ratio of } \geq 20: 1\end{array}$ & {$[21]$} \\
\hline
\end{tabular}

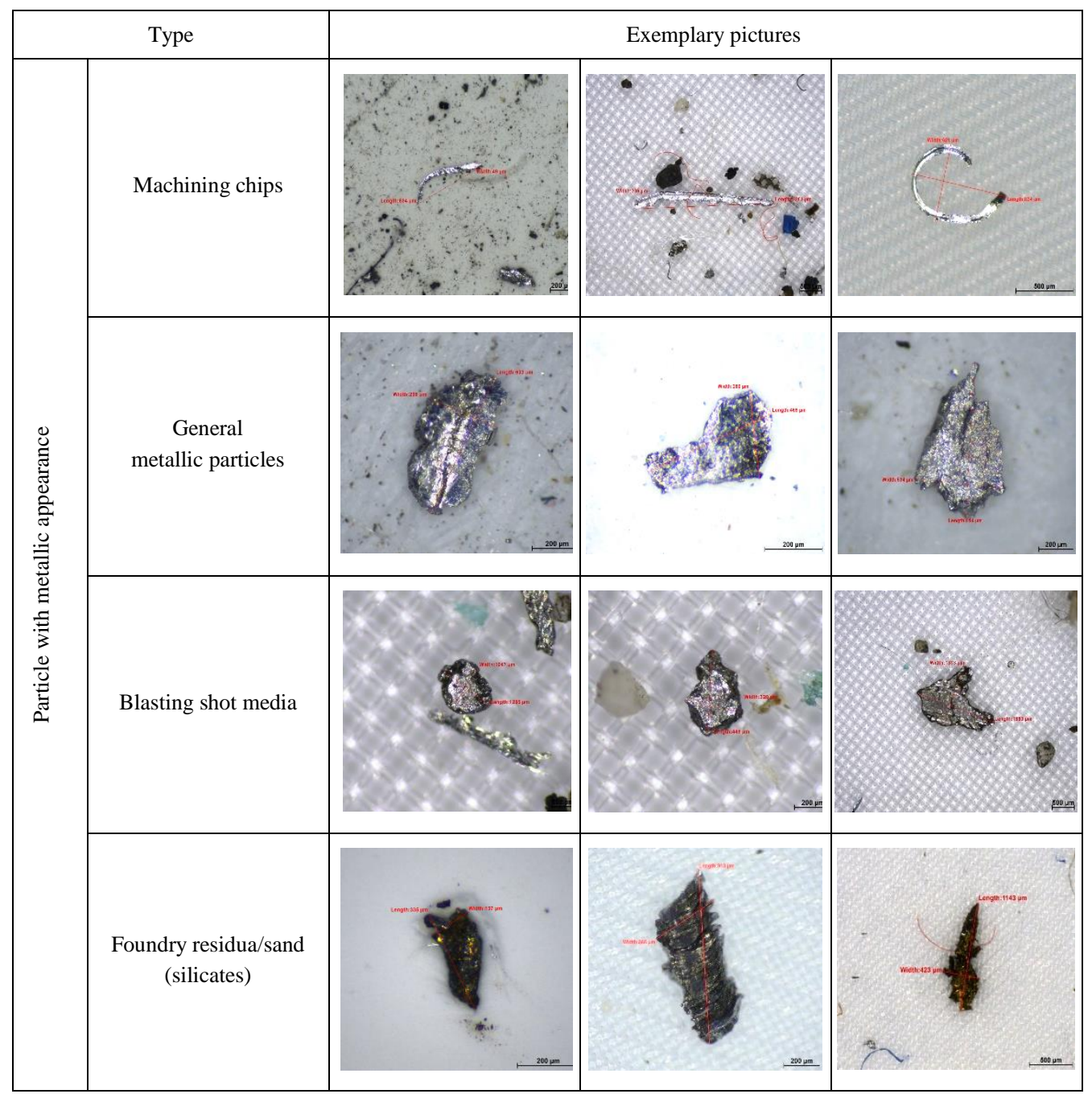

Fig. 2. Examples of hard (H) particles 


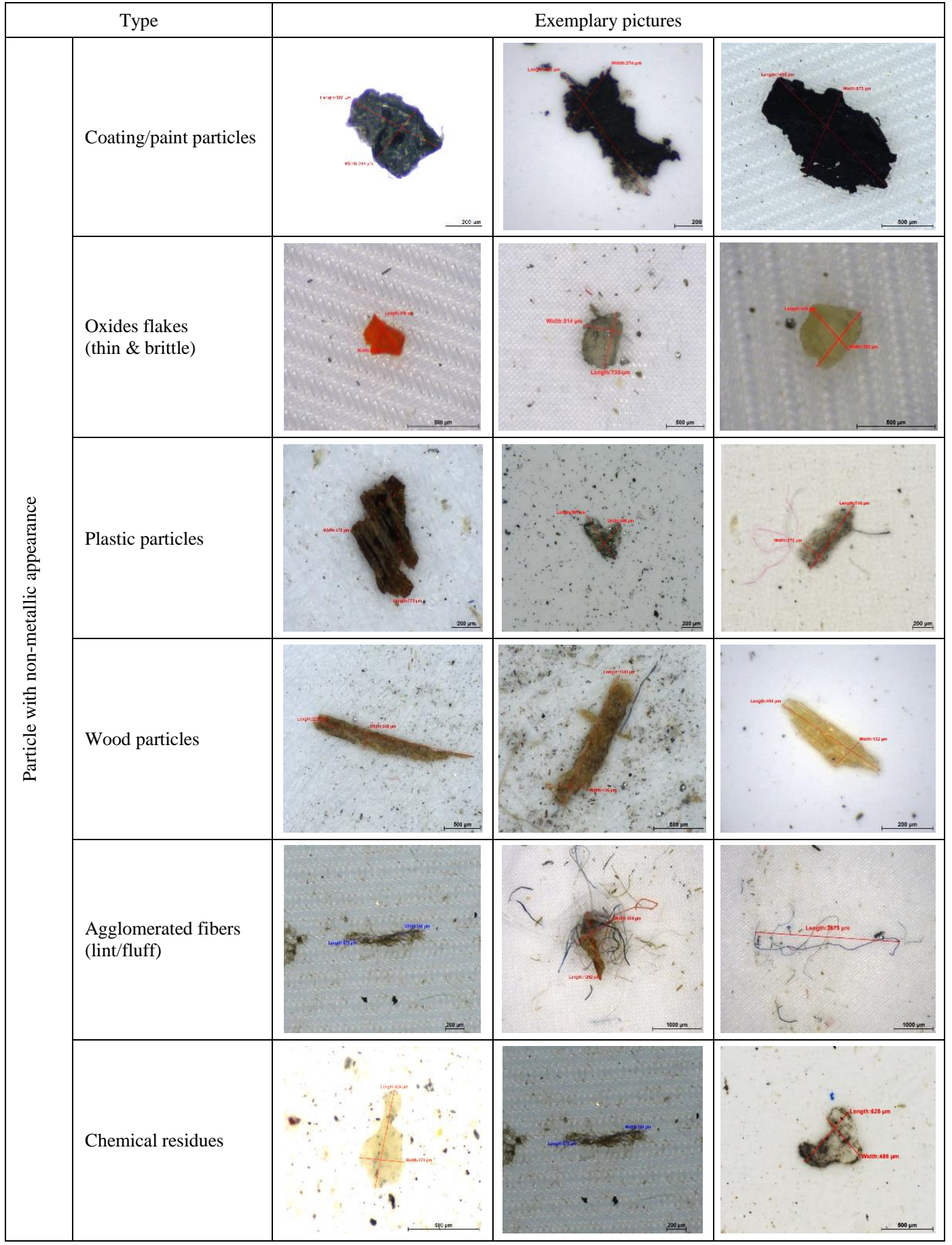

Fig. 3. Examples of soft (S) particles

\begin{tabular}{|c|c|c|c|c|}
\hline Type & \multicolumn{3}{|c|}{ Exemplary pictures } \\
\hline & & & \\
\hline & & &
\end{tabular}

Fig. 4. Examples of fibers 


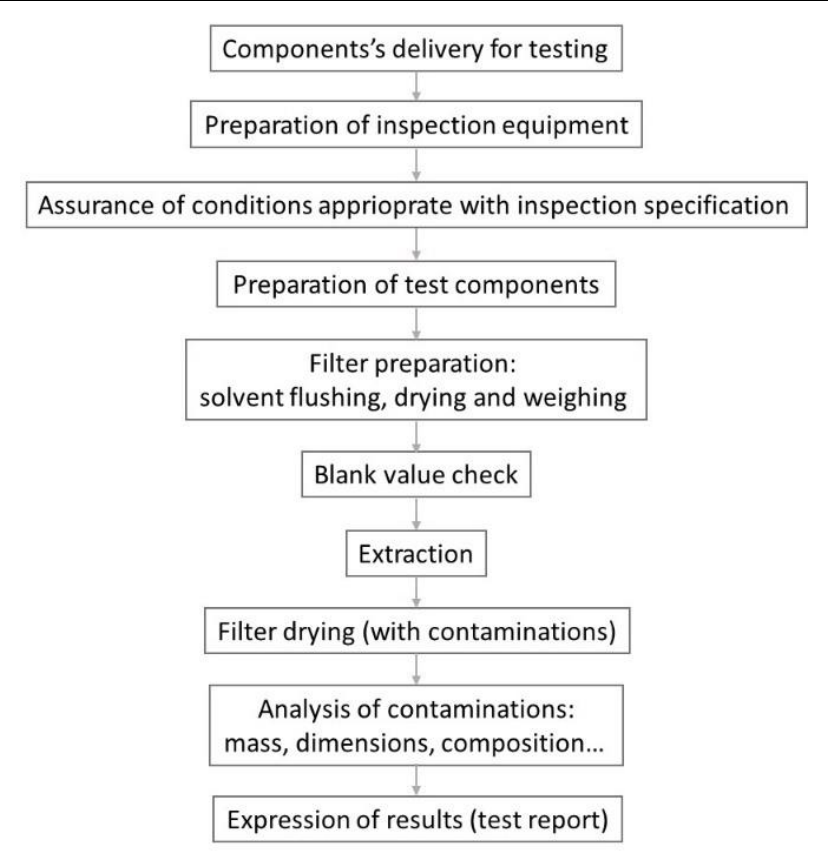

Fig. 5. Cleanliness inspection procedure

presumed sufficient while allows for removing of at least 90 percent of contaminations (see. p. 3).

The factors need to be taken into account when choosing the extraction method are, inter alia:

- surface to be tested: external, internal or total,

- tested object's size and geometry,

- material and particles adhesion.

Based on tested object characteristics (size, geometry) basic extraction methods can be applied:

- liquid extraction methods: agitation, ultrasonics, pressure rinsing, internal rinsing,

- air extraction methods: air jet, throughflow.

Depending on the required cleanliness level removed particles can be analyzed by:

- shortened analysis, with the use of liquid particle counters or camera (seldom applied in laboratory),

- standard analysis: gravimetry and light optical microscopic analysis,

- extended analysis, which can include such advanced techniques as light scanning electron microscopy with energy-dispersive X-ray spectroscopy (SEM-EDX), laser induced breakdown spectroscopy (LIBS), Raman spectroscopy, infrared spectroscopy (IR) or X-ray tomography.

Additional care needs to be taken when cleanliness analysis is focused also on liquid or greasy contaminations on the tested surface. Such cases are typical in many case studies which concentrate on indicating the failure causes of various objects. In some cases presence of foreign liquid is more dangerous for the component than foreign particulates as it may lead for example to lowering the friction of mated parts or malfunction of electronic devices. The later is especially important while the latest technological developments, including the increasing electrification of the powertrain is taken into account [1]. In this case the most important step is choosing the extraction liquid which should be able to dissolve/remove the substance from the surface. In the same time the solvent should be pure and volatile enough to allow its fast evaporation without any residues remaining which could influence the results. Typical analytical methods which could follow liquid extraction of such contamination is infrared spectroscopy (IR) or chromatographic techniques like gas chromatography (GC), high performance liquid chromatography (HPLC) or ionic chromatography (IC).

\subsection{Extraction methods}

Pressure rinsing seems to be the most common extraction method as it can be easily applied for both external and internal surface cleaning as long as surfaces are easily accessible. It can be also applied for multiple small components testing in bulk as long as they are characterized by simple geometries. Important factors influencing this method efficacy are:

- shape of pressure rinsing pistol nozzle (use of different shapes may be useful for large/small areas components or various geometries),

- test liquid characteristic (proper viscosity allowing fast drainage and proper wetting of the surface) and flow rate,

- angle and distance between nozzle and object surface,

- time of extraction and number of repetitions per surface.

In case of pressure rinsing the detachment of particulates is an effect of momentum transferred from the jet stream to particles. This technique is very flexible and allows to extract the contaminations even from small cavities if other surfaces are properly secured. Moreover, it is very effective for cleaning of objects with multiple areas to be evaluated separately from the same object.

In case of ultrasonic technique particles are detaching form the surface due to the high pressure peaks forming when cavitation bubbles implode. This method seems to be dedicated to simple geometries, and is ideal when total area of component need to be tested. However, more complicated objects with cavities could be subjected to this type of cleaning when openings diameters and cavities volume are taken into account while selecting the extraction parameters. In general, it is advisable that tested object has clearances large enough to guarantee that detached particulates will not remain on its surface due to any spherical barriers. This method could have unwanted effect on the surface of object as improper parameters could lead to surface or material damage, especially in case of coated surfaces and sintered materials. The lower ultrasonic frequency the stronger forces affects the particles and the more efficient cleaning become. That is why the most important factors for establishing efficient ultrasonic cleaning procedure are:

- ultrasonic frequency and density,

- locations of ultrasonic oscillators in bath,

- orientation of tested object versus ultrasonic source,

- type and temperature of test liquid,

- extraction time.

Internal rinsing is almost perfect choice for any automotive component which is designed for conducting flow. In this method component is filled with liquid at turbulent flow which allows proper particulates extraction. Relatively simple systems can be built in order to check cleanliness of 
tubing, lines, filters or even heat exchangers. However, in case of active components such as valves, injectors or pumps additional actions and functionalities may be required to perform the extraction from whole surface, which changes depending on the tested object status. In such case the extraction systems may be complicated and therefore costly and usually are designed on purpose of selected object testing. As requirement for turbulent flow always need to be taken into account complex benches may suffer from object geometry, large volumes and/or large diameters that may require large volumes of testing liquid as well as additional equipment allowing to reach the required liquid flow.

In case of this method care should be taken in selecting:

- test liquid,

- flow rate,

- extraction time,

- geometry of the component,

- connections used,

- pulsation frequency,

- type and characteristics of the movement in case of active components.

It is worth to notice that in the case of internal rinsing procedure risk of falsifying the results with contaminations from external surface is minimal.

In case of internal surface check of components with complex geometries and cavities, which are hard to reach by pressure rinsing, ultrasonic or internal rinsing, simple yet effective method of agitation can be used. Agitation of partially filled with testing liquid and completely sealed component allows the liquid to reach hard-to-reach zones and provide possibility of detaching contaminations' particles due to force acting from different directions and angles. Detached particles are then suspended in test liquid until removed and filtered. Depending on the weight and volume of the object manual or automated agitation may be used. This relatively simple method's efficiency is related to: test liquid used and its volume, time, duration, amplitude and frequency of agitation and number of object fillings with test liquid. It should be taken into account that this method is not preferred in case of small diameter tubes or narrow inner geometries.

In some types of components that are not intended for contact with liquids or may be damaged by such contact, air extraction should be applied. Two methods, similar to described above internal rinsing and pressure rinsing, can be used. First one is called air jet extraction and may be effectively used for cleaning electronic components or engine air intake tracts, from which particulates cannot be extracted with liquid flow through method. The basics of this method as well as factors influencing its efficiency are the same as in liquid pressure rinsing. The only change is in type of fluid which changed from liquid to air. This extraction procedure should be performed in hermetically closed cabinet like glove-box. Contaminations detached from tested surface are sticking to the wetted cabin's walls and in next step are rinsed and filtered with the test liquid. Second method of air extraction - air through-flow extraction is similar to internal rinsing with liquid. Air flow is detaching particulates from internal surface of the tested object which are then immobilized on large surface membranes which can withstand high air flow rates. In order to be able to perform analysis of contaminations, collected particulates are transferred to final filter by means of pressure rinsing. In both cases it is crucial to use clean, oil-free compressed air.

\subsection{Filtration}

In order to perform analytical verification of particulates, the particles need to be separated from the test liquid in which they are suspended. This operation is based on vacuum filtration on various types of filters and their meshes. Its selection is depending on the required cleanliness level - the ability to retain particles of interest, type of test liquid used - chemical resistance and also optical characteristics.

Despite the chemical resistance to the extraction liquid, the most important action is proper selection of the filter porosity. The filter used should allow retaining the smallest particles which are in the area of interest. It needs to be taken into account that particles usually have irregular shapes and their differentiation is based on the largest diameter. For that reason the actual filter porosity should be significantly lower than diameter of the smallest particle of interest. For standard gravimetric and microscopic analysis, where contaminants greater than $50 \mu \mathrm{m}$ are analyzed, the use of polyester (i.e. polyethylene terephthalate, PET) filters with a porosity of $5 \mu \mathrm{m}$ is recommended.

In general, foamed membrane or mesh filters can be used, both having its advantages and disadvantages. In case of foamed membrane which, due to its smooth surface, significantly eases microscopic analysis these cons are:

- good potential for absorbing pigment particles,

- lowering the contrast between its surface and particles,

- tendency for water absorption, what can influence gravimetric analysis.

On the other hand, mesh filters do not suffer from these problems as they absorb much less water and have defined pore size. These allows avoiding of small pigment particles retaining, but, with high magnification, their structure may cause reflections and artifacts. Moreover, some very thin particles may not be retained during filtration.

Basic types of filter materials with its chemical resistance are presented in Table 2, while exemplary view of mesh membrane filter is in Fig. 6.

Table 2. Filters types and their compatibility with test liquids [3]

\begin{tabular}{|c|c|c|c|c|c|c|}
\hline \multicolumn{2}{|c|}{ Filter material } & \multicolumn{5}{|c|}{ Test liquid } \\
\cline { 2 - 7 } & Aq. & Isopr. & Eth. & Aliph. & Ket. \\
\hline \multirow{3}{*}{$\begin{array}{c}\text { Foamed } \\
\text { membrane }\end{array}$} & $\begin{array}{c}\text { Cellulose } \\
\text { nitrate }\end{array}$ & + & - & - & - & - \\
\cline { 2 - 7 } & $\begin{array}{c}\text { Cellulose } \\
\text { acetate }\end{array}$ & + & + & - & + & - \\
\cline { 2 - 7 } & Polyamide & + & + & + & + & + \\
\hline \multirow{2}{*}{ Mesh } & Polyester & + & + & + & + & + \\
\cline { 2 - 7 } & Polyamide & + & + & + & + & + \\
\hline
\end{tabular}

+ compatible , - incompatible

Aq. - aqueous neutral cleaner, Isopr. - isopropanol, Eth. - ethanol, Aliph. - aliphatic hydrocarbons, Ket. - ketones (e.g. acetone) 


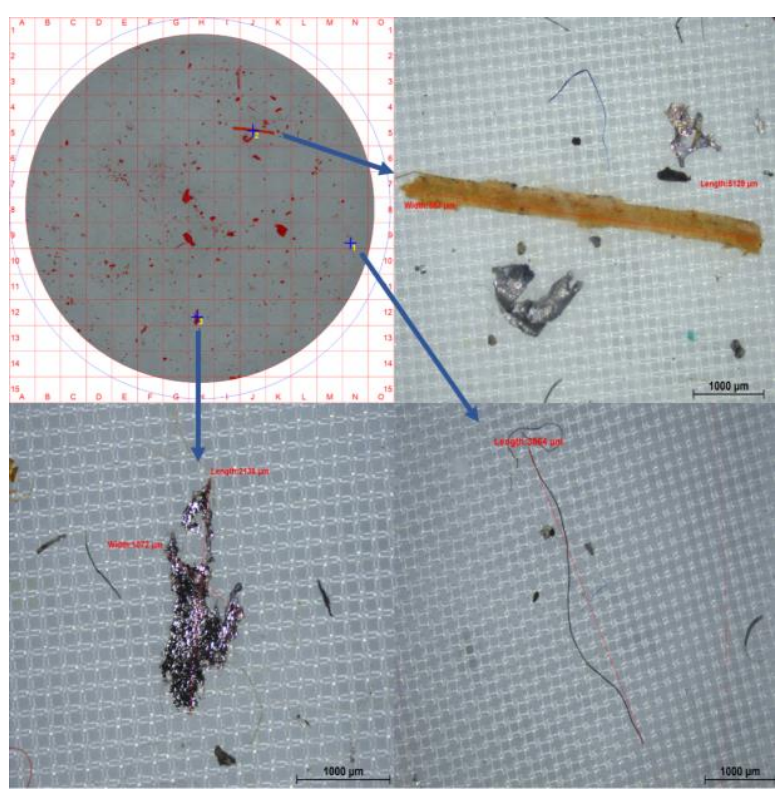

Fig. 6. Mesh membrane filter (overall view, upper left) with metallic (lower left), non-metallic (upper right) and fibrous (lower right) particles

\subsection{Analytical methods}

Gravimetric analysis is the simplest approach in standard analysis to cleanliness inspection and can include both particles and soluble contaminations assessment. The determination of total solid contaminations involves filtering the extraction fluid through a filter and calculating their weight by the difference in filter mass before and after the filtration process. An analytical balance with a minimum precision of $0.1 \mathrm{mg}$ is needed for accurate determination the differences in filter mass. What is very important, filters must be properly prepared for the test: first dried in an oven at specified temperature, then cooled down to the room temperature in desiccator. It is therefore important that temperature and humidity in the weighing room are both regulated and controlled. The filter drying temperature and time should be determined by a pre-selected procedure, taking into account the filter material and the type of extraction fluid used. Despite it's simplicity, gravimetric analysis gives information about overall component contamination.

Determination of soluble contaminants, such as grease, oil or degreasing residue, consists of collecting the prefiltered extraction fluid in appropriately dried and weighed beakers and calculating the difference in their mass as described above. Similarly, as in case of filters care must be taken in the preparation, drying and weighing of the beakers. Moreover, the inspection fluid has to be easily evaporated and chemically clean to avoid cross-contamination and interference with the results.

Light microscopic method is the basis of standard cleanliness inspection. Its application allows obtaining information regarding the number, sizes/size ranges and type of particles. All of this information is based on microscopic image analysis which, in order to be reliable, should be taken with proper contrast - differentiation of particles versus filter surface is based on grey scale. Filter for optical analysis should be properly prepared, and analyzed contaminations should be evenly distributed. Overload of particles as well as their overlapping do not allow obtaining reliable results.

In case of light microscopic analysis simple differentiation between solid metallic (shiny), non-metallic (nonshiny) and fibrous particles is based only on microscopic image and on pixels forming particle image. Metallic and non-metallic particles are usually distinguished with the use of two distinct images, e.g. polarized versus non-polarized, of the same particle. This analytical method as the most common has their disadvantages. Besides the ones described above, these are: the need of use of automated microscopic systems with motorized stages, homogenous and stable in time illumination of the whole filter surface during the whole analysis. This method will also suffer from particles presence which color is similar to the filter material, usually white. Some effort was made to overcome this issue and yellow mesh filters were introduced making the analysis of white contaminations much easier.

Even though automatic microscopic systems are required for image analysis and processing of results, well trained personnel is required as well. They role is very important and includes set up proper analytical parameters, like selecting the threshold, manual correction of some common mistakes like dividing mat and shining particle into two or more separate ones, or opposite - counting overlapped particles as one.

Extended analysis of particulates may be performed with light microscopic method in case of some additional requirements. For example, if particles height analysis is needed differences between the focus position of the filter and highest point of the particle are used. In some cases, for certain types of particles of interest additional measurements need to be taken with the use of various illumination modes or double check in order to obtain requested information.

Another measurement technique is scanning electron microscopy (SEM) analysis, which allows particles' counting, and measuring conjugated with $\mathbf{X}$-ray spectroscopy (EDX), which provides information about contaminations' elemental composition, and therefore its hardness. This advanced method is advised when additional information on particles composition is required in order to indicate more precisely their sources or to avoid presence of hard particles which may lead to component malfunction. Application of this technique allows verifying the presence of conductive particles which may interfere with electronic devices. As the SEM-EDX method counts particles on different contrast basis (material contrast) than light microscopy, results obtained by these two methods should not be compared. However, it is possible to verify elemental composition of selected particles measured by means of light microscopy if coordinates of these particles on the filter can be transferred to SEM-EDX equipment. As this method is more time consuming than light microscopy, additionally in case of high particle counts, only part of the filter needs to be analyzed. If the filter occupancy is homogeneous the corresponding results could be then extrapolated to the total filter area. Compromise between elemental composition results quality, the more X-ray impulses for 
each particle are counted the more reliable the results are, and total analysis time is needed.

It should be taken into consideration that classification of particles to different materials groups are based only on analyzed elemental composition which strongly depends on EDX detector resolution. Moreover, SEM-EDX have their own limitations in case of organic/plastic particles analysis. As the filters introduce the background containing a lot of carbon, and X-ray spectroscopy in general is less sensitive for lighter elements like oxygen, carbon and nitrogen, only specific plastic materials could be distinguished. Among them are those containing some other elements, like chlorine (i.e. PVC), or fluorine (i.e. PTFE). The comparison of light microscopy and SEM-EDX analysis of the same particle is presented in Fig. 7.

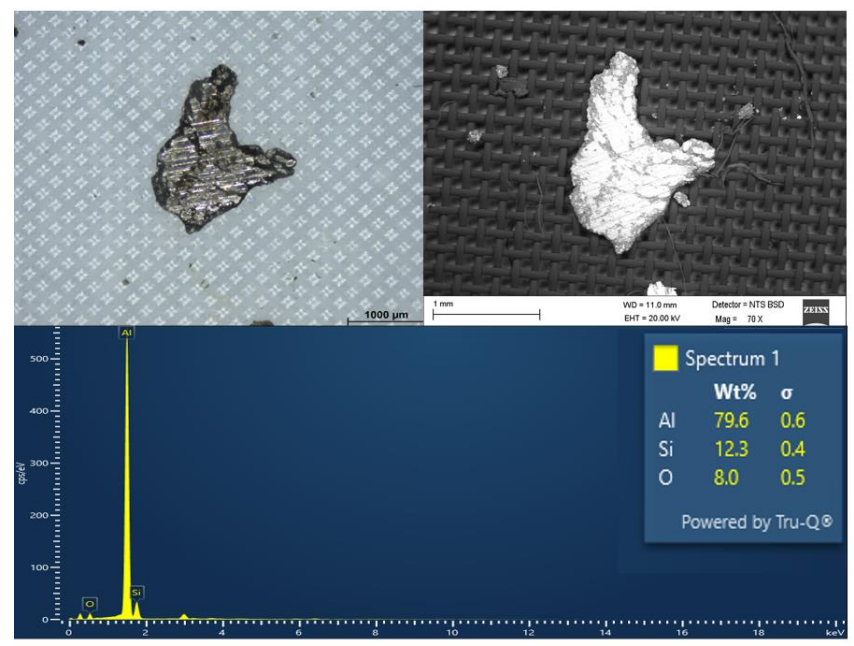

Fig. 7. Comparison of particle view from light microscopy (upper left) and SEM-EDX (upper right and bottom)

Other method allowing to obtain information about particle elemental composition, and hence it's physical characteristic, is laser induced breakdown spectroscopy (LIBS). In this case high energetic laser pulse vaporizes particle and generates plasma, which spectrum is analyzed. This method allows much faster (less than second) elemental composition analysis than SEM-EDX which measurement quality is dependent on time. Moreover, SEMEDX requires multiple-point analysis on particles to gather quality results what takes from one to few seconds per particle. LIBS is generally nearly non-destructive method as only small portion of material is ablated from the analyzed surface [22]. However, with high energies and very small particles, some of them may be destroyed during analysis and this do not allow repeated analysis or any additional measurement as impact craters with diameter of $20 \mu \mathrm{m}$ and depth of $10 \mu \mathrm{m}$ are analyzed for each particle [3]. Therefore, this method allows gathering precise results very fast, what is important in many areas when decision needs to be taken as fast as possible. However, in case of disputes possibility of losing some evidence collected during cleanliness inspection may be risk that is not acceptable by the independent laboratory. LIBS, as the previously described methods, requires proper particles separation on the filter in order to provide reliable results and is well suited for analysis of particles not smaller than $15 \mu \mathrm{m}$.

In opposition to LIBS, which is sensitive for elemental composition, especially of pure metals and inorganic materials, Raman spectroscopy also based on laser excitation allows determination of organic and inorganic molecules but in this case pure metals do not generate signal. Identification of particles material is based on comparison of obtained spectra with database. Raman spectroscopy is well fitted for analysis of particles even as small as $0.5 \mu \mathrm{m}$ but the typical time for single contamination analysis ranges from 30 to 60 seconds. This means that cleanliness inspection based on Raman spectroscopy will take similar time as typical SEM-EDX analysis. However, this is the first method from described above which allows identification plastic materials, what could be necessary in some processes to find source of component contamination.

Another method also using measurement of molecular vibrations to identify the compounds is Fourier transform infrared spectroscopy (FTIR). The disadvantage of this method is that it does not allow analysis of such small particles as Raman spectroscopy but is much more common and relatively cheaper. FTIR is sensitive for organic groups presence in tested molecules and particles, allowing identification not only plastic particles material but also solvents, greases, oils or even contaminated particles. This method is not well suited for analysis of inorganic materials. In general two infrared techniques may be used: transmission or attenuated total reflectance (ATR). Both may be applied in IR microscopes and IR spectrometers. In general, the use of IR spectrometer is limited to particles than can be removed from the filter (for example with tweezers) and transferred to IR spectrometer. In case of ATR technique, the particle is then pressed against the crystal (diamond crystal is common example) allowing transfer of IR irradiation to the analyzed sample and back to the detector. In case of transmission technique, which is usually more sensitive and provides better quality spectra, IR radiation is passing through the particle pressed by two crystals.

\section{Quality control and quality assurance}

In order to confirm correctness of cleanliness test performance, quality control and assurance (QC\&QA) need to be implemented. It is not easy aspect because although component cleaning procedure is not destructive activity, it cannot be repeated for the same test component, because particles are removed from the component and the present state of component cleanliness has been changed [3]. So, in fact, other elements of QC\&QA need to be performed. Some of them are described in ISO 16232 [3], and the others result from good laboratory practice.

Elements of QC\&QA include, but are not limited to:

- blank value control,

- validation of cleaning procedure (declining curve),

- cleaning procedure control (double inspection),

- balance control,

- microscope control and calibration,

- check of length standard,

- analysis of particles standard, 
- microscopic analysis of repeated sample (reproducibility test),

- personnel training.

One of the most important things in cleanliness inspection is blank value control. This parameter check is required by all standards and specifications in cleanliness field, and is defined as a maximum value that may not be exceeded (usually maximum $10 \%$ of measured or expected value of total particle mass and number for component tested). It is not required before each routine test, but should be checked regularly, especially in case of high CCC requirements or when equipment was not used for some time.

Blank value check is proof for:

- high purity of external environment in cleanroom,

- purity of extraction liquid,

- purity of equipment used,

- proper control of cleaning procedure.

It is worth to mention, that the cleanliness test does not always have to be performed in cleanrooms, with defined cleanliness class according to ISO 14644-1 [15]. It may also be carried out in separated areas. For that reason the blank value check is very important as this will reflect possible environmental effects, that means if external contaminants are not introduced into the component under test.

Another required by the standard activity is validation of cleaning procedure (qualification test). The aim of this procedure is to select:

- proper extraction liquid quantity,

- proper extraction time,

- proper extraction procedure,

- proper extraction parameters.

The aim of validation procedure is also to check if maximum amount of particles was extracted from component, which means that effectiveness of particle extraction is evaluated. As a result, extraction (declining or decay) curve is determined (example of such curve is presented in Fig. 8).

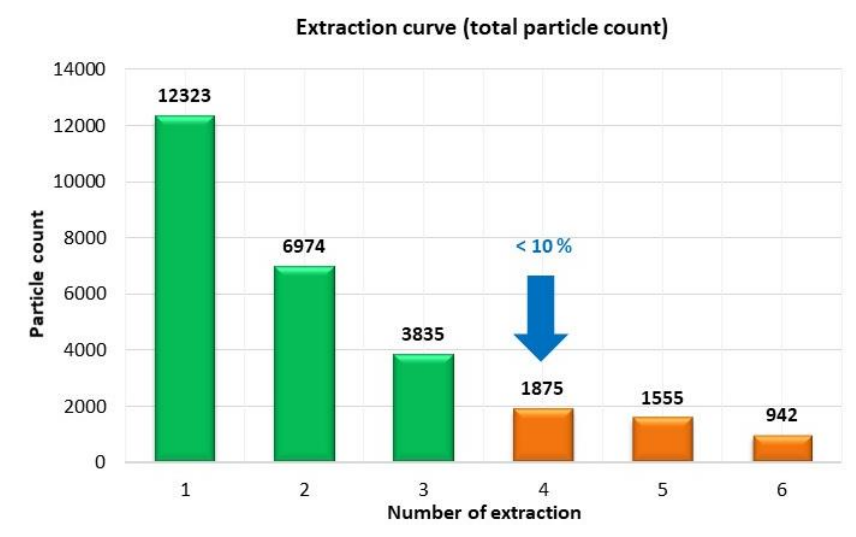

Fig. 8. Example of declining curve

Validation procedure is usually performed on one component, sometimes on i.e. 5 different components. During this procedure, component is cleaned minimum 3 times, but usually 6 times, and particles extracted are collected on 6 different filters. If extraction procedure is performed correctly, total amount of particles extracted should decrease successively, reaching a point where the amount of extract- ed contaminants is less than $10 \%$ of the total amount of contaminants extracted in all previous extraction steps, including the current step, according to Equation 1 [3]:

$$
\mathrm{C}_{\mathrm{n}} \leq 0.10 \sum_{\mathrm{i}=1}^{\mathrm{n}} \mathrm{C}_{\mathrm{i}} \quad \mathrm{n} \leq 6
$$

The validation procedure together with blank value check is carried out at least once for each component or family of components. However, it should be noticed that if any design change or change in the manufacturing process is introduced, the qualification test should be repeated.

Double inspection is another procedure for cleaning performance check, and is performed for routine check of selected parameters. In this test one component is cleaned twice, and after second cleaning total amount of particles extracted should not be higher than $30 \%$ of the sum of particles from first and second cleaning, according to Equation 2 [3]:

$$
\mathrm{C}_{2} \leq 0.30\left(\mathrm{C}_{1}+\mathrm{C}_{2}\right)
$$

Example of double inspection results are presented in Fig. 9.

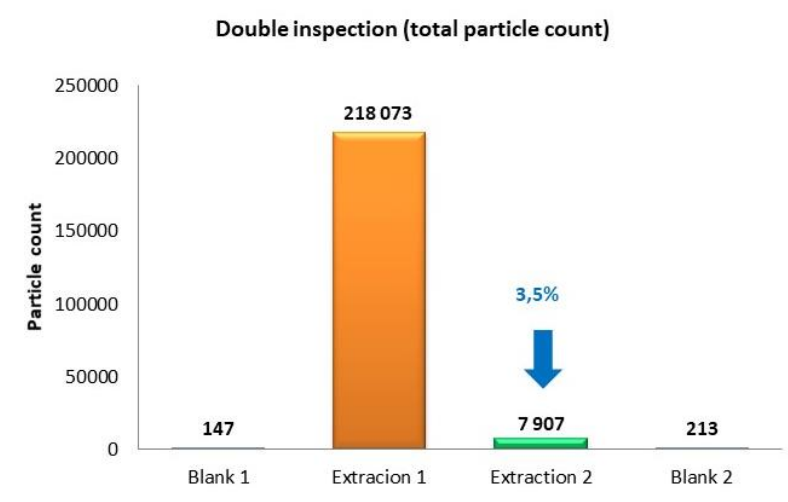

Fig. 9. Example of double inspection results

One of the most important things in technical cleanliness inspection, especially emphasized in ISO standard, is staff skills and training. The procedure of staff training includes many aspects, from understanding the importance of technical cleanliness and requirements, having knowledge of procedures and standards, being aware of all steps in cleanliness inspection, to choosing the test liquid and extraction parameters and interpretation of results obtained and so on. Because technical cleanliness is a complex and complicated topic, well-educated and motivated staff is crucial.

\section{Conclusions}

The development of the automotive industry entails increasing demands in scope of technical cleanliness of various components. In-depth analysis of contaminations is required more and more frequently, with simple gravimetric analysis being too scarce.

Reduction of particulates presence on components' surfaces is costly and only understanding of their sources, processes required for their removal and cleanliness testing methodology can lead to cost minimization. Even though the pursuit for the best cleanliness is not wrong, it should be always taken into account that the components should be as 
clean as required and not necessarily as clean as possible. In each case the independent and reliable results of cleanliness inspection are always required to serve as the best source of information regarding the surface preparation.

\section{Nomenclature}

CCC component cleanliness code

SEM scanning electron microscope

EDX energy dispersive spectroscopy

FTIR Fourier transform infrared spectroscopy

LIBS laser induced breakdown spectroscopy

IR
HPLC high performance liquid chromatography

GC gas chromatography

IC ionic chromatography

QC quality control

QA quality assurance

\section{Bibliography}

[1] KOBLENZER, G. Trends in automotive parts cleaning. IST International Surface Technology. 2017, 10, 36-37. https://doi.org/10.1007/s35724-017-0012-4

[2] PEČMAN, J., LUPTAK, V. Cleanliness test for variable packing solutions in the automotive supply chain. The Archives of Automotive Engineering. 2021, 91, 49-62. https://doi.org/10.14669/AM.VOL91.ART4

[3] International standard ISO 16232. Road vehicles - cleanliness of components and systems. 2018.

[4] VDA Automotive standard VDA 19.1. Inspection of Technical Cleanliness. Particulate Contamination of Functionally Relevant Automotive Components. 2015.

[5] DZETZIT, A., NAGIT, G. Research on importance of cleanliness in manufacturing reliable products for automotive. MATEC Web of Conferences. 2017, 112, 09017. https://doi.org/10.1051/matecconf/201711209017

[6] STATHIS, A., KOUlOCHERIS, D., COSTOPOUlOS, T. et al. The impact of particle contaminants' hardness on the wear mechanism of rolling element bearings. International Journal of Mechanical and Electrical Engineering. 2014, 1(1), 10-19.

[7] ORAVEC, M., DIVOKOVA, A., LIPOVSKY, P. et al. Technical cleanliness - a requirement of precision manufacturing. Acta Mechanica Slovaca. 2019, 23(4), 46-51. https://doi.org/10.21496/ams.2020.008

[8] FABER, J., BRODZIK, K. Elemental analysis as an important tool for fuels and biofuels quality control. Combustion Engines. 2017, 171(4), 140-144.

https://doi.org/10.19206/CE-2017-423

[9] TUNG, S.C., TOTTEN, G.E. Automotive lubricants and testing. SAE International. 2012.

[10] FABER, J., SALA, R., KRASOWSKI, J. The influence of chlorine-contaminated fuel on $\mathrm{NO}_{\mathrm{x}}$ emission control elements in compression engine. Autobusy - Technika, Eksploatacja, Systemy Transportowe. 2018, 6, 414-420. https://doi.org/10.24136/atest.2018.104

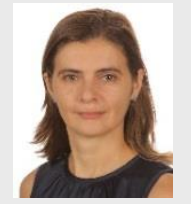

Krzysztof Brodzik, DEng. - Materials Testing Department, BOSMAL Automotive Research and Development Institute Ltd, Bielsko-Biała, Poland. e-mail: krzysztof.brodzik@bosmal.com.pl
[11] STĘPIEŃ, Z. The influence of particulate contamination in diesel fuel on the damage to fuel injection system. Combustion Engines. 2019, 177(2), 76-82. https://doi.org/10.19206/CE-2019-213

[12] STĘPIEŃ, Z., ŻÓŁTY, M. Examination of particulate contaminations contents in commercial diesel fuel. TribologiaFinnish Journal of Tribology. 2020, 37(3-4), 37-44. https://doi.org/10.30678/fjt.91711

[13] LEE, J.-C., SHIN, H.-M. An experimental investigation on the contamination sensitivity of an automotive fuel pump. International Journal of Precision Engineering and Manufacturing. 2005, 6(3), 51-55.

[14] HYDAC International GmbH. Technical cleanliness: These days no longer an option, but an obligation. E 10.110.1.0/07.13

[15] International standard ISO 14644-1, Cleanrooms and associated controlled environments - Part 1: Classification of air cleanliness by particle concentration. 2015 .

[16] VW Standard PV 3347, Cleanliness of Engine Components. Determination of Residual Particle Quantities. 2019.

[17] BMW Standard QV 11 111, Appropriate Technical Cleanliness of Components and Fluids in BMW Power Train. 2020.

[18] Mercedes-Daimler Standard DBL 6516, Specification of Residual Dirt Limit Values. 2018.

[19] GM Standard GMW 16037, Test Method to Quantify Cleanliness of Engine and Transmission Components. 2017.

[20] Standard Volvo Group STD 107-0002, Contamination control. Cleanliness of components and systems. Test method. 2018.

[21] Scania specification STD4540, Specification and determination of technical cleanliness in media carrying systems. 2019.

[22] KOHLI R., MITTAL K.L., Developments in surface contamination and cleaning. Vol. 12: Methods for assessment and verification of cleanliness of surfaces and characterization of surface contaminants. Elsevier, Amsterdam 2019. https://doi.org/10.1016/C2017-0-03847-8

Marta Nycz, MEng. - Materials Testing Department, BOSMAL Automotive Research and Development Institute Ltd, Bielsko-Biała, Poland. e-mail:marta.nycz@bosmal.com.pl
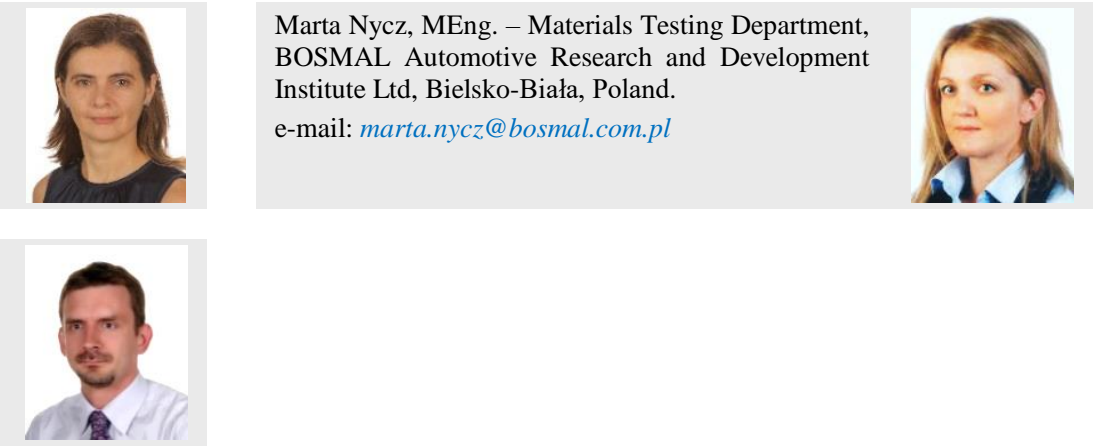